\title{
Takotsubo cardiomyopathy: What should myocardial perfusion imaging reveal
}

\author{
Kazuya Takehana, MD, PhD \\ a Division of Cardiology, Department of Medicine II, Kansai Medical University, Hirakata, Osaka, \\ Japan
}

Received Oct 28, 2020; accepted Oct 28, 2020

doi: $10.1007 / \mathrm{s} 12350-020-02435-3$

\section{See related article, pp. 1034-1046}

Transient left ventricular (LV) apical ballooning syndrome, also known as takotsubo cardiomyopathy, was first described in the early 1990s in Japan. ${ }^{1}$ The LV adopts the shape of a "takotsubo" [in Japanese, "tako", means octopus and "tsubo" means pot; takotsubo is the pot that Japanese fishermen use as an octopus trap (Figure 1)]. The syndrome receives this name because of the morphological similarity between this object (narrow neck and broad base with a globular form) and the LV during ventricular systole (on echocardiography and ventriculography). It is also known as ampulla cardiomyopathy, a name referring to the wide-bodied, narrow-necked container used in ancient Greece and imperial Rome. Since ancient times, octopus has been an extremely popular food in Japan, and Japan is the largest consumers of octopus in the world. Japanese people do not have a bad image in octopus like 'devil' fish, so we affectionately call it takotsubo cardiomyopathy (TCM).

While a widely established non-invasive tool allowing a rapid and reliable diagnosis of TCM is currently lacking, coronary angiography with left ventriculography is considered the gold standard diagnostic tool to exclude or confirm TCM. Abe et al. introduced the first diagnostic criteria for TCM in 2003 . $^{2}$ Several criteria have been published since then; the Mayo Clinic Diagnostic Criteria are the most applied. ${ }^{3-5}$ The conventional criteria have proposed the exclusion of

Reprint requests: Kazuya Takehana, MD, PhD, Division of Cardiology, Department of Medicine II, Kansai Medical University, 2-5-1 Shinmachi, Hirakata, Osaka 573-1010, Japan; takehana@hirakata.kmu.ac.jp

J Nucl Cardiol 2022;29:1047-50.

$1071-3581 / \$ 34.00$

Copyright (c) 2021 American Society of Nuclear Cardiology. significant stenosis of the coronary artery; however, the recent data have demonstrated that ACS is frequently observed in patients with TCM. ${ }^{6}$ Variant forms of TCM, known as "inverted takotsubo" or "midventricular ballooning syndrome,', have been described. ${ }^{7}$ These include the midventricular, basal, and focal wall motion patterns. These patients are younger, suffer more often from neurologic comorbidities, have lower brain natriuretic peptide values, a less impaired LVEF, and more frequent ST-segment depression compared to typical TCM. $^{8}$ In-hospital complication rate is similar between typical and atypical types, while 1-year mortality is higher in typical TCM.

Clinical presentation of TCM should be distinguished from acute coronary syndrome (ACS), therefore, nuclear imaging markedly contributes to the accurate diagnosis. However, no diagnostic criteria have been established the usefulness of nuclear imaging in TCM diagnosis, which is already discussed. ${ }^{7-9}$ We have also reported several studies using nuclear imaging technique, ${ }^{10,11}$ and representative case is shown in Figure 2. 84-year-old woman with precordial atypical pain showed apical asynergy on TTE. The myocardial SPECT imaging revealed apical defect of myocardial blood flow at rest by ${ }^{99 \mathrm{~m}}$ Tc-tetrofosmin (Figure $2 \mathrm{~A}$ ) and relatively greater defect of ${ }^{123}$ I-BMIPP (Figure $2 \mathrm{~B}$ ). Invasive coronary angiography revealed an absence of significant organic stenosis in the epicardial coronary arteries and apical ballooning on ventriculography. After 3 weeks optimal medical treatment, apical ballooning on TTE was disappeared and myocardial perfusion defect was completely disappeared (Figure 2C). 

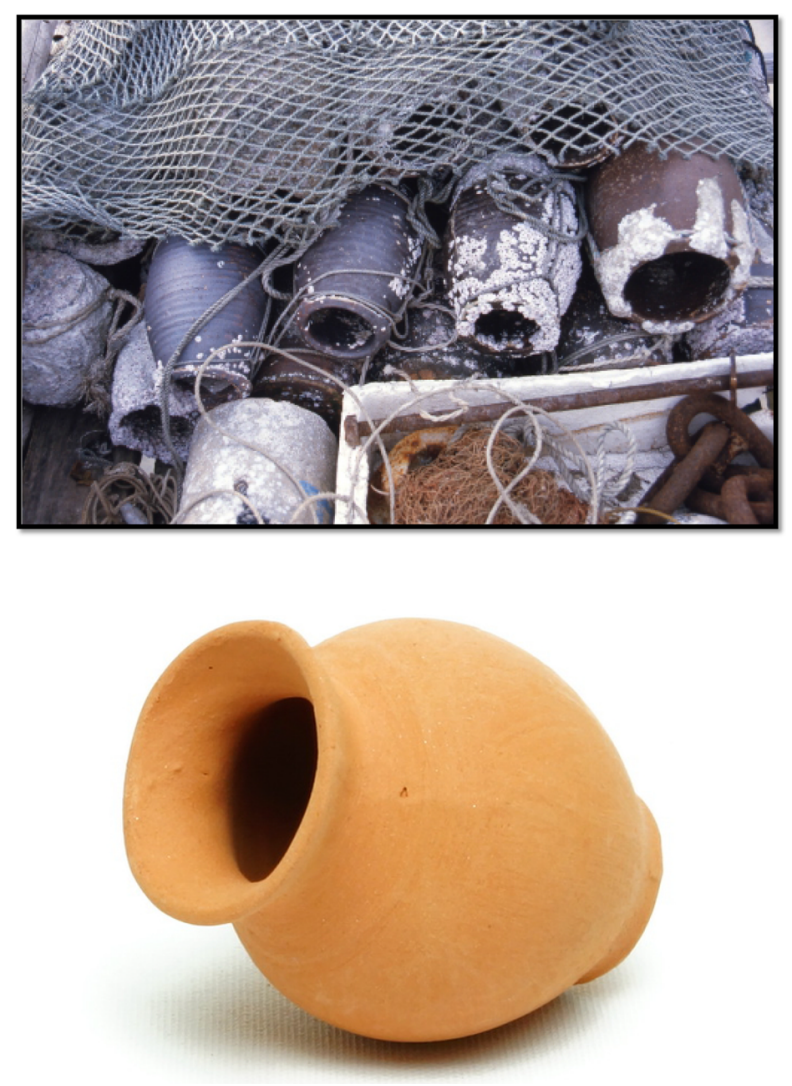

Figure 1. Traditional Japanese fishermen use as an octopus trap.
In this issue of the Journal of Nuclear Cardiology, Anderson et al. reported that a systematic case series review of TCM patients in their electronic medical records from multiple facilities serving a $>2$ million patient population within the states of Utah and Idaho. Who underwent an MPI as part of their diagnostic evaluation. ${ }^{12}$ Since their searched data was from 2009 to 2019 , TCM was diagnosed only 16 patients from over 2 million cases. Recurrence rate of TCM is estimated to be $1.8 \%$ per-patient year. ${ }^{6}$ As the authors mentioned, it is thought that the cause of the underestimation was that the disease concept of TCM was not commonly known at that time except Asian countries.

A hypothesis about reduction of apical counts occurs by regional myocardial wall thinning in the apex, which is due to not the artifact but the partial volume effects, or due to reduced regional perfusion in the takotsubo infarcted area and increased perfusion in nontakotsubo area or combined all these factors. ${ }^{13}$ Since there have been few reports on myocardial blood flow evaluation in patients with TCM using Rb-PET perfusion imaging, especially adenosine stress, I hope that this RPS for TCM cases will lead to the elucidation of the pathophysiology of TCM. 

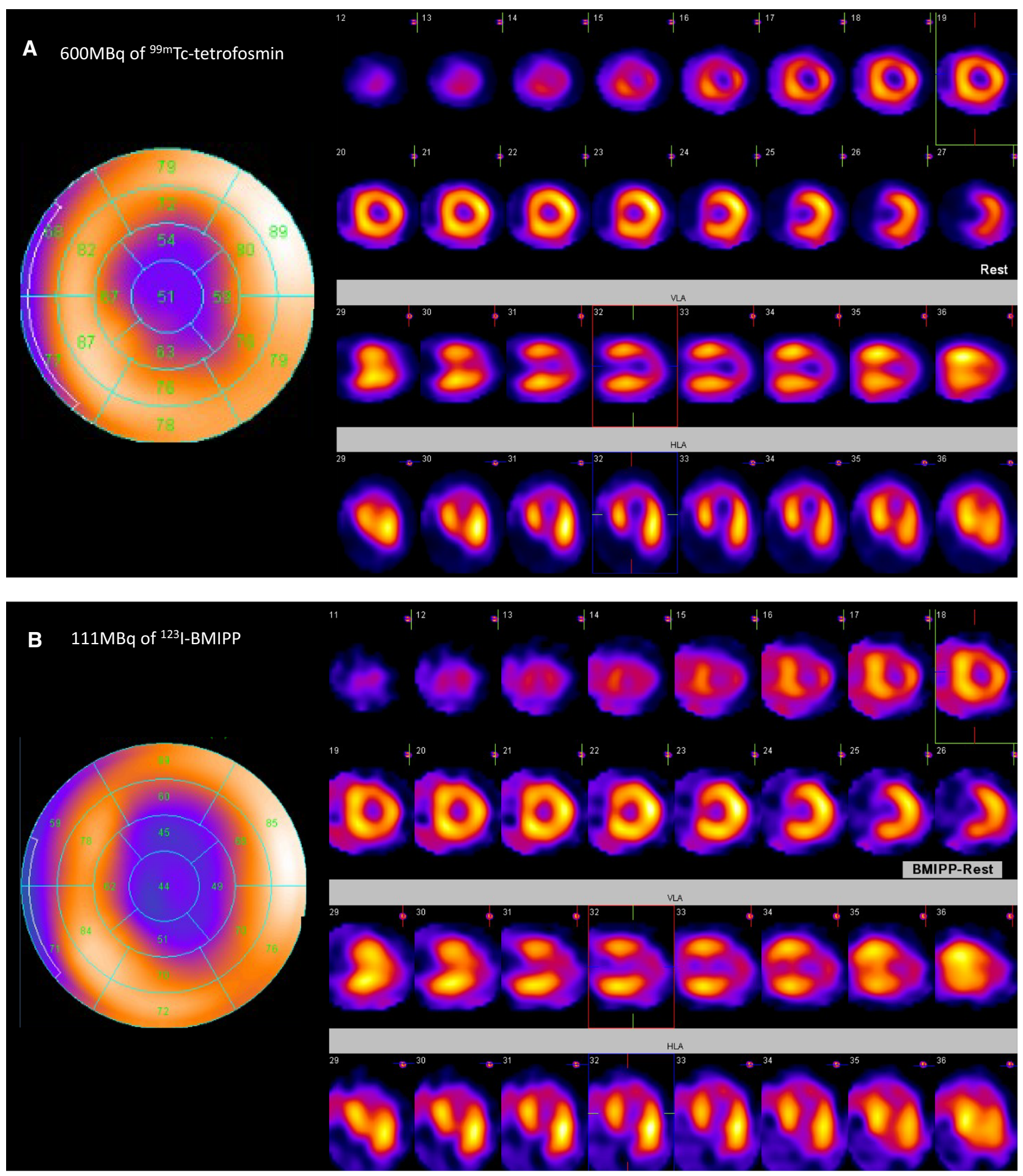

Figure 2. Representative example of myocardial perfusion scintigraphy with ${ }^{99 \mathrm{~m}} \mathrm{Tc}$-tetrofosmin (A) and ${ }^{123}$ I-BMIPP (B) in a patient with Takotsubo cardiomyopathy. Figure A and B were sequentially acquired in a 84-year-old woman presenting atypical chest pain. Typical LV apical ballooning was observed in TTE study. Fatty acid metabolism imaging showed severe apical defect compared with Tc-perfusion imaging (metabolism and flow mismatch). 21 days after admission, apical ballooning was disappeared in TTE and normal perfusion was demonstrated with Tc perfusion imaging $(\mathbf{C})$. 


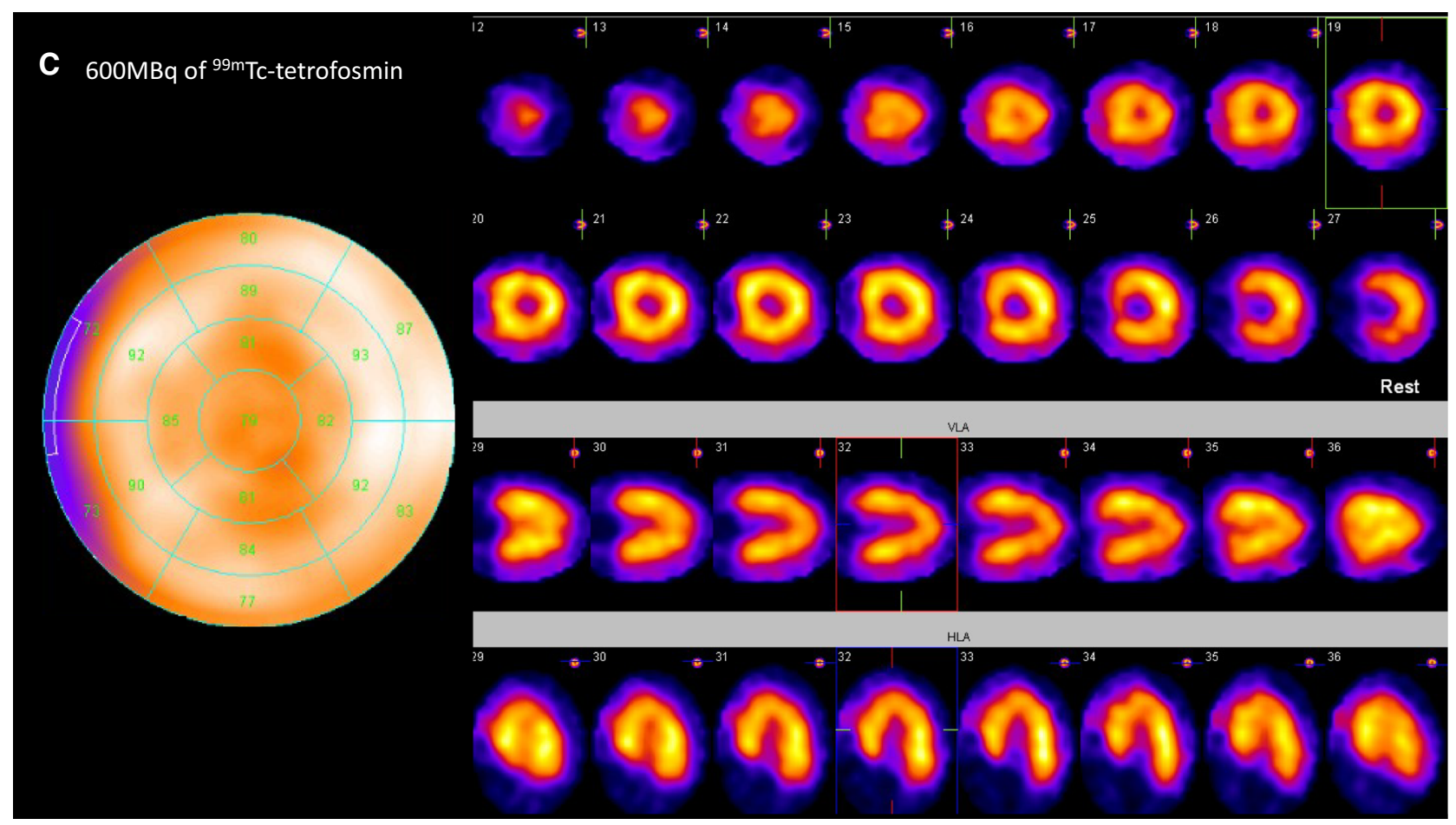

Figure 2. continued.

\section{References}

1. Dote K, Sato H, Tateishi H, Uchida T, Ishihara M (1991) Myocardial stunning due to simultaneous multivessel coronary spasm: A review of 5 cases. J Cardiol 21:203-214 ([in Japanese with English abstract])

2. Abe Y, Kondo M, Matsuoka R, Araki M, Dohyama K, Tanio H (2003) Assessment of clinical features in transient left ventricular apical ballooning. J Am Coll Cardiol 41:737-742

3. Kawai S, Kitabatake A, Tomoike H, Takotsubo Cardiomyopathy Group (2007) Guidelines for diagnosis of takotsubo (ampulla) cardiomyopathy. Circ J 71:990-992

4. Prasad A, Lerman A, Rihal CS (2008) Apical ballooning syndrome (tako-tsubo or stress cardiomyopathy): A mimic of acute myocardial infarction. Am Heart J 155:408-417

5. Ghadri JR, Wittstein IS, Prasad A et al (2018a) International expert consensus document on Takotsubo syndrome (Part I): Clinical characteristics, diagnostic criteria, and pathophysiology. Eur Heart J 39:2032-2046

6. Templin C, Ghadri JR, Diekmann J et al (2015) Clinical features and outcomes of takotsubo (stress) cardiomyopathy. N Engl J Med 373:929-938

7. Ghadri JR, Cammann VL, Napp LC et al (2016) International Takotsubo Registry. Differences in the clinical profile and outcomes of typical and atypical Takotsubo syndrome: Data from the International Takotsubo Registry. JAMA Cardiol 1:335-340
8. Ghadri JR, Wittstein IS, Prasad A et al (2018b) International expert consensus document on Takotsubo syndrome (PART II): Diagnostic workup and outcome, and management. Eur Heart J 39:2047-2062

9. Lyon AR, Bossone E, Schneider B et al (2016) Current state of knowledge on Takotsubo syndrome: A position statement from the Taskforce on Takotsubo Syndrome of the Heart Failure Association of the European Society of Cardiology. Eur J Heart Fail 18:827

10. Fukui M, Mori Y, Tsujimoto S et al (2006) "Takotsubo" cardiomyopathy in a maintenance hemodialysis patient. Ther Apher Dial. 10:94-100

11. Maeba H, Takehana K, Kanazawa T et al (2012) Atypical morphology and myocardial perfusion of mid-ventricular ballooning. JC Cases 6:e70-e74

12. Anderson JL, Benjamin DH, Le VT et al (2020) Spectrum of radionuclide perfusion study abnormalities in Takotsubo cardiomyopathy. J Nucl Cardiol. https://doi.org/10.1007/s12350-02002385-w

13. Okuyama K, Akashi YJ (2018) Takotsubo syndrome: Changes in diagnostic criteria and role of nuclear imaging. Ann Nucl Cardiol 4:101-104

Publisher's Note Springer Nature remains neutral with regard to jurisdictional claims in published maps and institutional affiliations. 